\title{
Academic Procrastination of Students from the Standpoint of the Subject-Activity Approach
}

\section{Galina Gotfridovna Alexandrova}

\author{
Kazan Federal University, 18 Kremlyovskaya St., Kazan 420008, Republic of Tatarstan, Russian Federation
}

\section{Doi:10.5901/mjss.2015.v6n3s1p113}

\section{Abstract}

The paper proposes a theoretical basis for considering the phenomenon of procrastination of a personality from the standpoint of the subject-activity approach. According to this approach, the nature of human activity should be described within the parameters of his or her personality as a subject of activity, which is carried out within the framework of this activity, as well as taking into account the content and role of the activity in the life of this person. The ability of a personality to direct and control different forms of its activity is regarded as an indicator of an individual subjectivity. The author summarizes the results of an empirical study of the tendency to academic procrastination, motivation to training and ability to self-management in a select query of university students, according to which: 1) the index of academic procrastination is in inversely ratio to the indices of the capability for self-management; 2) self-management system is directly related to the motive of acquiring professional knowledge and skills; 3) high levels of academic procrastination are accompanied by a pronounced focus on obtaining a diploma with a formal approach to the process of training itself and poorly formed system of self-management.

Keywords: procrastination of a personality, academic procrastination, subject-activity approach, academic activity, capability for self-management, motivation for training.

\section{Introduction}

In the context of rising competition in the labor market the question of training in a particular professional field always was and still remains relevant. The problems of monitoring and optimization of the process of professional training are attracting the attention of practitioners in the field of specialized secondary school and university education, as well as the representatives of a scientific community, including a psychological one. In order to find the way to raise the effectiveness of the learning activities of university students it is necessary to conduct the study of the whole complex of conditions that will either assist or hinder this process. Among the internal factors associated with success rates of higher school training, is the phenomenon of academic procrastination. In general terms, it is understood as a process of putting off by students the fulfillment of class assignments. [1].

E.P. Ilin [2] suggests that academic procrastination is among the most significant factors that present learning difficulties for students. The author refers to the results of studies, according to which from $46 \%$ to $95 \%$ of students in secondary and higher educational institutions show a steady tendency toward procrastination and recognize it as their problem. According to N.N. Karlovskaya and R.R. Baranova [3] data, procrastination is not only the reduction of academic achievements, but it also increases the neuroticism and degrades the overall well-being of students. The research made among university students showed that academic procrastination leads to an increase in the level of anxiety, low selfesteem (often - before the formation of an inferiority complex), and even to giving up further studies [4]. These facts justify the practical relevance of studying the phenomenon of procrastination in the context of the effectiveness of professional higher school education.

Historical foray into the documentary record of procrastination or "the syndrome of tomorrow" held by P. Steel [5], gave him reasons to assume that the phenomenon has a long history and, furthermore, is common enough. In the early 80-ies of the last century, first modern publications on the problem of procrastination appeared, then the problem gets scientific and methodological development, and in the last decade this subject attracted the attention of psychologists in Russia as well. However, in the arsenal of the modern psychological science, some studies on the issue of academic procrastination reveal a number of significant controversies concerning in particular the relationship between propensity for procrastination and characteristic features of a personality. So S.B. Mokhova A.N. and Nevryuev [4] present data showing that in one of the studies $89 \%$ of trainees in the series of gifted students admitted in they feel a tendency for procrastination, while in another study there was no statistically significant correlation between the level of procrastination and intelligence. Even more: in the group of students with high intellect procrastinators turned out to be less than $20 \%$. In 
addition, J. Perri [6] identifies two types of procrastinators - "relaxed" ones and "tense" ones. He directly connects their tendencies to procrastination with the lack of self-confidence, fear of failure, feeling of guilt and dissatisfaction with themselves. The author suggested considering procrastination in correlation with a negative self-evaluation. And according to the study of J. Sokolowska [7], the more confident are the students, the more they believe in their efficiency, the greater is the possibility that they will put off the fulfillment of learning assignments till the last moment.

The differences are observed both in the methodological approach to research and assessment of general, as well as academic procrastination. Some techniques $[8,9]$ have been criticized in terms of the reliability of the measurement, others $[10,11,12]$ - with respect to the theoretical construct, lying in their base. However, to the credit of the authors of the techniques, they have stressed very important features of procrastination as a phenomenon: the aspect of the purpose and necessity of the not accomplished tasks [11], differences in personal reasons for putting off. [8] As for the methods of measuring the academic procrastination, their authors also made a significant contribution to improving diagnostic tools and understanding of the phenomenon as a whole: the need to clarify the types of academic activity, and taking into account of self-estimation of procrastination as an academic problem [12], the necessity in such techniques that could be easily adapted for self-assessment.

Such state of scientific and practical problems in the study of academic procrastination made it possible to determine the subject, purpose and objectives of the study. The subject of the research is as follows: the psychological content of the phenomenon of academic procrastination. The objective is to clarify the substantive aspect of the phenomenon of academic procrastination on the basis of subject-activity approach, and in the context of interpretations of this phenomenon presented in modern psychological science. The theoretical task is to prove the possibility of considering academic procrastination from the standpoint of the principle of activity (of the subject) and the psychological theory of activity. Empirical problem is to examine how academic procrastination is related to motivation and training in universities and the ability to self-management as a characteristic feature of subjectivity of a personality among university students, as well as to identify the motivational and subject characteristics of students with different levels of academic procrastination.

\section{Theoretical and Methodological Basis of the study}

The term "procrastination" is derived from the Latin word combination procrastinatus: pro - (instead of, ahead) and crastinus (tomorrow) and means "a tendency to constant putting off unpleasant thoughts and tasks" [5, p.65]. The overview of approaches and studies on procrastination showed that there are both similarities and differences in the interpretation of meaning. The uniqueness concerns such aspects of the phenomenon, which certainly can be considered as basic in its understanding. Firstly, this is what can be called the subject of procrastination - actions that some authors have used in a broad sense $[6,8,11,13,14]$, and others specified them in the form of thoughts, decisions, as well as directly in the form of actions and tasks [1,5]. With regard to academic procrastination an attempt was made to clarify the character of tasks within a specific (educational) activity in relation to which the phenomenon can occur [12]. Secondly, most authors agree that procrastination involves on the one hand the person's understanding of the importance of the performance of specific tasks, actions, and negative consequences, i.e. risks for themselves in case of nonaccomplishment $[1,6,11,14,15]$, and on the other - putting off their implementation over time. They recommend explaining such motivational paradox as an emotional reaction to perform actions due to these or those reasons $[5,6,8,15]$. Thus, the essence of the procrastination phenomenon can be described by such psychological categories as "action", "activity" and "motivation".

These are concepts that regarded as are key ones in the activity approach, which for half a century has been developed in the Russian scientific psychology. Most holistically it was implemented in A. N. Leontiev psychological theory of activity [16]. We will present here the basic principles of this theory.

Human activity has a hierarchic structure, which consists of four levels: special activities, actions, operations and psycho physiological functions, where every previous activity overmasters the following. Educational or training activity can be regarded as an example of special (specific types) of activities.

The action category is a fundamental one and means the process that is directed on achieving the goal, which in its turn represents the desired image. Goals of a person are according to their nature and scale, i.e. hierarchically, and can be accepted as a consistent formation. Series of corresponding actions is organized in this way and it forms a hierarchical system of actions. The operation is a method by which actions are performed; it is defined by external and internal conditions. The activity, as well as actions, can differ in form: internal (mental) and external (practical). For example, internal actions can have an aim of working out an intellectual solution, but at the same time they can fulfill the preparatory function of transition to practical actions. The connection of special activities, goals, actions and campaigns is 
organized by the complex of motives, the character of interrelations of which determinates special aspects of actualization of this activity.

The conception of "action" in the theory of activity is in line with the principles of activity (of the subject), where the defining role in human activity is given to internal sources contrary to external motivations. A human being's characteristic features are developing and manifesting themselves mainly in how he or she takes part in organization and realization of their activities, taking into account the level structure of the activity.

Let's consider the phenomenon of academic procrastination, using the strategies of this psychological theory of activity. According to D.B. Elkonin[17], educational or training activity in general is the activity of mastering generalized methods of learning procedures in the process of performing academic tasks, which are given from outside in terms of external control and assessment, then turning into self-control and self-esteem. Thus, in the course of training, development of the trainee's personality also takes place.

As for an educational activity of students in higher educational institutions, it is focused on the formation of knowledge system and skill acquirement for their appropriate theoretical and practical use in professional activities. The result of the whole training period of education at the university is reflected in the objective index of student's effectiveness - the University diploma. Together with professional and personality evolution, the university diploma can be regarded as a desired result (the aim) of all academic activity in a higher educational institution. The solution of specific tasks is required for achieving these important goals. Attempts were made to describe the complex of learning activities for students [12], but mainly they were marked on the basis of forms of control (pass-fail exams, tests, term papers and so on) or other objective indices. But for the analysis of academic procrastination not only the content of educational activities is important, but also the interrelations of educational activities levels. Therefore, the postponement of fulfillment of important tasks or other educational activities could be defined as a specific character of realization not only of the given activities, but for all activities of the student altogether.

The significance of motivation in goal-oriented activities has been already described above. According to T.I. llina [2], the main types of motivation in studying at universities are: a motive of getting knowledge (the desire to acquire general knowledge), a skills development motive (the desire to master the professional knowledge and create professionally important qualities), the motive of getting a diploma (the wish to get a degree in the formal digestion of knowledge). The author believes that the predominance of the first and second motives demonstrates the interest of the student in the profession and of its conscious choice.

It would not be quite correct to suppose that the phenomenon of academic procrastination clearly implies a predominance of getting a diploma. A formal approach of a student to a learning process implies his or her emotional indifference to educational problems. But the phenomenon of procrastination is understood as putting off the performance of an action together with the recognition of its importance for you. Thus, not only the extent of these motives, but also their correlation with each other will determine the nature of fulfillment of activities for students. The situation when a person puts off an important for him activity can be described as a situation of conflict of motives. In terms of educational activities such conflict, in turn, will be reflected as at the level of learning activities, so at the level of operations as well.

It is possible to settle the conflict with the active (subjective) participation of the student. For university students the subjective essence acquires special significance, since their entry and continued participation in educational activities is carried out on the basis of voluntary choice. By studying the nature of students' motivation, R. Klassen and colleagues [14] concluded that academic procrastination is primarily a problem of motivation, and in order to overcome it, it is necessary to develop the student's autonomy of motivation. It is active (subjective) participation in a learning process which will make student able to achieve their goals and enjoy it. But this means that the self-organization is to do not just with the system of goals and motives, actions and operations, but also with the system of educational activities in general. According to L.M. Popov [18], besides traditionally set tasks of higher school education - professional training, in modern conditions more important is the ability of students to initiate and manage their professional and personal development, that is, to become mature subjects in their life's journey. N.D. Dzhiga [19] reasonably considers self-management as a factor in the success of training and development of the student.

N.M. Peysahov [20] developed a theoretical construct of the personality as the subject of management of various forms of its mental activity and offered appropriate methodological tools to assess the ability of the individual to selfmanagement. This process of self-management is regarded as the system of stages which, on the one hand, can be conducted sequentially, whereas on the other hand in each subsequent stage a return to the previous one can happen.

The author distinguishes the following stages of self-management:

- the analysis of the situation (understanding and assessment of the problem and possibilities of a person to solve them);

- the forecasting (considering various options for the outcome of the situation taking into account the different 
degrees of activity of the person's participation);

- the goal-setting (choosing a prompt individual goal on the basis of correlation of previously considered possible outcomes of the situation with the actual needs and, most importantly, with the existing life goals, i.e. the adjustment of objectives of different levels and the establishment of a task system);

- the planning (defining the complexity and nature of internal and external resources required to achieve the selected target);

- the evaluation criteria (specifying the parameters of a relevant goal, which will be used in evaluation of intermediate and final results);

- the decision-making (defining the readiness and initiation of the activity to achieve the desired result);

- the self-control (assessing the progress towards the goals and interim results);

- the correction (revising the results of previous stages, making all the necessary changes and the further implementation of already corrected actions).

Of particular importance in the context of the problem of procrastination is the transition phase of preparatory actions (interpretation of the forthcoming activity) to real, practical actions. The author emphasizes that the rashness of the real action, as well as putting them off in time, indicates the absence or inefficiency of the preparatory work, and as a consequence - the inconsistency between the internal and external plan, and therefore the inconsistency of the entire system of management as a whole. In our study on the subjectivity of knowledge [21] a direct correlation of the ability to control oneself with indicators of the results of learning and satisfaction of a student with his or her activity has been revealed. Besides, systemically important function of the ability of a person to govern himself in a complex of other indicators of subjectivity - adequate internality, independence in thoughts and deeds, attitude towards himself and others as subjects of his daily life activities - has been proved.

With regard to the problem of academic procrastination, we are inclined to consider indicators of the ability of university students to self-management as elements enabling to clarify the psychological essence of this phenomenon and to identify the most problematic areas in the system of self-management among students that could previse their tendency to procrastination.

\section{Method}

In accordance with the selected theoretical foundations of the study a psycho diagnostic complex was developed for solution of empirical problems. The complex includes the following methods: "The scale of academic procrastination (APS)" (Justin D. J. Mccloskey) [22], "The Motivation for studying in the university" (T.I. llina, E.P. llin) [2], "The ability to self-management (SSA)" (N. M. Peysahov) [20]. Third and fourth year students of various universities (training areas) have been chosen as subjects in the study. The age of the participants was from 20 to 23 . The total amount of a control group was 168 people. After calculating the primary data in terms of academic procrastination, it was found out that the control group was represented by subjects with different levels of academic procrastination. To identify the characteristics of motivation for studies and the ability to self-management among students with different levels of academic procrastination 3 groups with 30 students each (group 1 - with a low level, group 2 - with an average level, Group 3 - with a high level of academic procrastination) were drawn out of the control group. A statistic comparison of the indices under investigation was used according to Student's t-test. The linear correlation coefficients by Pearson were counted in order to check the nature of the correlation of academic procrastination indicators with motivation to studying in the university and the ability to self-management.

\section{The Results of Empirical Research}

The correlation analysis of indicators of motivation, capacity for self-management and academic procrastination in the control group of students revealed the following:

- The value of the "getting the general knowledge" motive directly correlates with the "learning of trade" motive $(p \leq 0,05)$, which, in its turn, is inversely related to the "diploma or graduation" motive $(p \leq 0,001)$. This indicates that the expressed desire of inquisitive students to get first of all professional knowledge and skills involves not a formal approach to the achievement of training results, and, therefore, implies their readiness to fulfill learning tasks. However, the absence of a direct statistically significant relationship between the "general knowledge" motive and the "diploma" motive shows that a student's formal approach to academic studies can not exclude his or her expressed intellectual curiosity, which they will tend to satisfy beyond the educational process. 
- All figures of the ability to self-management turned out to be directly correlated ( $p \leq 0,01$ and $p \leq 0,001$ ), moreover the most significant links were found between the indicators of separate stages and the overall capacity for self-management. This shows that the level of development of the ability to inner actions (forecasting, goal setting, planning) appears in the corresponding character of the transition to practical actions, their evaluation and correction, which affects the whole self-management system altogether.

- The self-management system is associated with the "learning of trade" motive through immediate direct links $(p \leq 0,01)$ of this indicator with such stages 0 self-management as goal setting, forecasting and planning. Thus, the desire of students to get professional knowledge and skills actualizes their internal (preparatory) work for an adequate transition to practical learning activities start to take the form of well-judged and deliberate move.

- The index of academic procrastination explicitly inversely correlates with the such stages of self-management as forecasting $(p \leq 0,01)$, goal setting $(p \leq 0,001)$, planning and evaluation criteria $(p \leq 0,01)$, decision-making and overall ability to self-management $(p \leq 0.001)$. This indicates that the degree of professional orientation, combined with the highly developed level students' self-management, i.e. their ability to organize the apprehension of tasks and further fulfill in practice their thought-out implementation, determining their tendency to academic procrastination.

- The analysis of mean values and statistical comparison of indicators of motivation and the ability to selfmanagement among students with different levels of academic procrastination revealed the following:

- The predominant motives in students with high and medium academic procrastination are the motives "the diploma' and "the knowledge proper'. Moreover, in students with high procrastination level "the diploma" orientation is above the orientation on knowledge, and in students with an average procrastination - the situation is vise versa. In the group of students with low indices of procrastination the greatest expression falls on the motive "the learning of trade", then comes "the knowledge proper" motive and "the diploma" motive, provided that the orientation on getting general knowledge in the expression is closer to "the diploma" orientation, than to the orientation on "learning the trade". Profession orientation is significantly higher ( $p \leq 0$, 01) in the group of students with low procrastination, than in other two groups. The remaining motives did not manifest any significant diversity. Thus, students with different levels of procrastination differ in the nature of academic study motivation, and hence it is the lack of orientation on getting professional knowledge and skills, even against the background of a simple intellectual curiosity that is characteristic for the students who are subjected to procrastination.

- Significant differences $(p \leq 0,05$ and $p \leq 0,01)$ or stable tendencies towards them are revealed in groups of students with different levels of academic procrastination according to all indicators of ability to selfmanagement: the analysis, the forecasting, the goal setting, the planning, the evaluation criteria, the transition to a practical action, the self-correction and the overall ability to self-management. Thereat the nature of these differences is in compliance with the level of procrastination found in the correlation analysis: the higher the academic procrastination, the lower the indicators of the self-management system.

The analysis of expressiveness and pertinence of self-management indicators in the group of students with a high level of procrastination has revealed the fact that the indicators of performance capacity for self-management have a low or lower than the average level of expressiveness, and their integratedness (the number and strength of links between them) is less than in the control group. Thereat the indicator of the transition to practical actions bears no significant relation to the performance of internal activity - the goal setting and the forecasting. This testifies about the lack of maturity of self-management in these students. Thus, the results of solutions of empirical problems made it possible to reveal motivational and subjective features of university students, who have tendencies to academic procrastination as well as to clarify psychological contents of the phenomenon.

\section{Conclusion}

1. The psychological essence of the procrastination phenomenon can be described from the standpoint of the subject-activity approach, according to which the nature of human performance should be described in the parameters of his or her personality as a subject of activity, within the framework of which this activity is carried out, as well as taking into account its content and role in the life of this person. The procrastination phenomenon understood as putting off particular matters and specific actions that are significant for him presents a violation of the activity system and its specific levels: goals, motives, actions and operations. The tendency of a person to procrastination is determined not so much by the objective content of the specific levels, but by the degree of its activity (subjectivity) in the organization of the whole activity system. 
2. The academic motivation of university students who are inclined to academic procrastination is dominated by "the diploma" motive and "the knowledge proper" motive rather than the desire to get professional knowledge and skills. Pronounced orientation of students on getting a diploma, which implies a formal approach to the academic activities and class assignments, combined with a greater or lesser intellectual curiosity is manifested in their predisposition to putting off learning activities with a greater or lesser degree of their diversity correspondingly.

3. The ability to self-management as an indicator of subjectivity in university students is inversely related to their inclination for academic procrastination. Students with high levels of academic procrastination showed a weakly formed self-management system, as is proved by low and below the average indicators of its single elements, as well as by the lack of links between the stages of anticipatory apprehension of specific tasks and stages of their practical decisions. All this points to the fact that such students come with an insufficiency of independent activity (subjectivity) in shaping their attitude to the educational process and participation in it.

Sustainable practical relevance of the problem of procrastination among school children and university students involves further active work in the field of this scientific and methodological study. As promising lines for research, we see the following: clarification of the nature of the educational process from the point of view of other participants, who interact with the knowledge pursuer subject and the conditions of educational environment as a whole, as well as their evaluation by students in the context of the procrastination phenomenon. In addition, research in the field of self-comprehension in students who have problems with academic procrastination can also contribute to the development of the techniques of practical correction and prevention of this phenomenon in university environment.

\section{Acknowledgement}

The author expresses her thanks to Guzel Almazovna Gallyamova for active assistance in carrying out the research.

\section{References}

N. Milgram, N. Naaman, Typology in procrastination, Personality \& Individual Differences, 20 (1996) 679-683.

E.P. Ilin, Trade and Personality. Workaholism, perfectionism, laziness, Peter, Saint Petersburg, 2011, 224.

N.N. Karlovskaya, R.A. Baranova, The relationship between general and academic procrastination and anxiety among students with different academic performance, Psychology in University, 3 (2008) 38-49.

S.B. Mokhova, A. N. Nevrueev, Psychological correlates of general and academic procrastination among students, Problems of psychology, 1 (2013) 24-35.

P. Steel, The nature of procrastination: A meta-analytic and theoretical review of quintessential self-regulatory failure, Psychological Bulletin, 133(1) (2007) 65-94.

J. Perry, The Art of Procrastination: A Guide to Effective Dawdling, Lolligagging and Postroning, Workman, New York, 2012, 112.

J. Sokolowska, Behavioral, affective, cognitive, and motivational dimensions of academic procrastination among community college students: $A Q$ methodology approach, Dissertation Abstracts International, 70(6) (2009) 1-147.

A. Chu, J. Choi, Rethinking procrastination: Positive effects of "active" procrastination behavior on attitudes and performance, Journal of Social Psychology, 145 (2005) 245-264.

B. Tuckman, The development and concurrent validity of the procrastination scale, Educational and Psychological Measurement, 51 (1991) $473-480$.

J. Choi, S. Moran, Why not procrastinate? Development and validation of a new active procrastination scale, Journal of Social Psychology, 149(2) (2009) 195-211.

C. Lay, At last, my research article on procrastination, Journal of Research in Personality, 20 (1986) 474-495.

L.J. Solomon, E. D. Rothblum, Academic procrastination: Frequency and cognitive-behavioral correlate, Journal of Counseling Psychology, 31 (1984) 503-509.

J. Ferrari, Procrastination in the workplace: Attributions for failure among individuals with similar behavioral tendencies, Personality and Individual Differences, 13(3) (1992) 315-319.

R. Klassen, L. Krawchuk and S. Rajani, Academic procrastination of undergraduates: Low self-efficacy to self-regulate predicts higher levels of procrastination, Contemporary Educational Psychology, 33 (2008) 915-931.

P. Steel, The Procrastination Equation: How to Stop Putting Things Off and Start Getting Stuff Done, HarperCollins, New York, $2011,320$.

A.N. Leontiev, Activity. Consciousness. Personality. Politizdat, Moscow, 1977, 304.

D. B. Elkonin, Child Psychology, Akademia, Moscow, 2006, 384.

L.M. Popov, E.N. Ibragimova, The psychology of intellectual and assignment evolution of the student, Scholarly notes of Kazan University, Humanities. Sciences, 149(1) (2007) 5-19.

N.D. Dzhiga, Self-management, self-modification of student's personality as a factor of successful development, Knowledge. Competence. Skills. 3 (2009) 206-210.

N. M. Peysahov, M.N. Shevtsov, Practical psychology: (Science basics), Kazan University Publishing House, Kazan, 1991, 121.

G. G. Aleksandrova, Psychological criteria of social maturity of a personality in modern Russian society, Scholarly notes of Kazan University, Humanities. Sciences, 149(1) (2007) 34-45.

J. Mccloskey, Academic Procrastination: the development of a scale, LAP LAMBERT Academic Publishing, 2012, 100. 